\title{
Rosai-Dorfman disease presenting with extensive cutaneous manifestation - Case report ${ }^{*}$ \\ Doença de Rosai-Dorfman com manifestação cutânea extensa - Relato de caso
}

\author{
Paula Azevedo Borges Leal ${ }^{1}$ \\ Marcelle Parente Breckenfeld ${ }^{1}$ \\ Antônio Renê Diógenes de Sousa ${ }^{3}$
}

\author{
Adrilena Lopes Adriano ${ }^{1}$ \\ Igor Santos Costa ${ }^{2}$ \\ Heitor de Sá Gonçalves ${ }^{4}$
}

\begin{abstract}
Rosai-Dorfman disease is a benign, self-limited, idiopathic proliferative histiocytic disorder. It was first described in 1969 by Rosai and Dorfman. In its typical form the disease is characterized by extensive cervical lymphadenopathy associated with fever, polyclonal gammopathy and leukocytosis with neutrophilia. The skin is the most common site affected. Extranodal manifestations have been reported in $43 \%$ of cases. In this study, we report an atypical case of Rosai-Dorfman disease in a female with massive cutaneous manifestation on the thigh, associated with a minimal lymphadenopathy limited to the regional inguinal lymph nodes.

Keywords: Emperipolesis; Histiocytosis; Histiocytosis, non-langerhans-cell; Histiocytosis, sinus

Resumo: A doença de Rosai-Dorfman é uma desordem benigna, autolimitada, idiopática, decorrente da proliferação de histiócitos. Foi descrita pela primeira vez por Rosai e Dorfman em 1969. Tipicamente, a doença se caracteriza por extensa linfadenopatia cervical, febre, gamopatia monoclonal e leucocitose com neutrofilia. Manifestações extranodais são encontradas em $43 \%$ dos casos, sendo a pele o sítio extranodal mais comumente afetado. No trabalho, apresentamos um caso de doença de Rosai-Dorfman com apresentação cutânea exuberante na coxa direita e discreto comprometimento linfonodal limitado à cadeia regional.

Palavras-chave: Emperipolese; Histiocitose; Histiocitose sinus; Histiocitose de células não Langerhans
\end{abstract}

\section{INTRODUCTION}

Sinus histiocytosis with massive lymphadenopathy (SHML) was recognized by Rosai and Dorfman in 1969 as a benign and self-limiting disease. It was characterized by extensive cervical lymphadenopathy associated with fever, polyclonal gammopathy, and leukocytosis with neutrophilia. ${ }^{1}$ SHML or Rosai Dorfman disease (RDD) is a rare pseudolymphomatous disorder of unknown etiology which is classified as non-Langerhans cell histiocytosis. The disease can affect any age group but young adult men are more susceptible to it; however, it rarely affects people of Asian origin. ${ }^{2}$
In its typical form, lymphadenopathy is bilateral, massive and painless, commonly affecting the cervical lymph nodes. ${ }^{3}$ Extranodal manifestations have been reported in $43 \%$ of cases, with the skin being most frequently affected. ${ }^{4}$ But, RDD only involves both nodal and extranodal sites in $28 \%$ of patients. ${ }^{5}$ In this study, we report an atypical case of RosaiDorfman disease in a female with massive cutaneous manifestation on the thigh, associated with a minimal lymphadenopathy limited to the regional inguinal lymph nodes.

\footnotetext{
Received on 14.01.2012.

Approved by the Advisory Board and accepted for publication on 30.04.2012.

* Study conducted at the Dona Libânia Dermatology Center (CDERM) - Fortaleza (CE), Brazil.-

Conflict of interest: None

Financial funding: None

Resident physician, second year Dermatology Residency of the Dermatology Department of the Dona Libânia Dermatology Center (CDERM) - Fortaleza (CE), Brazil.

MD Pathologist, Dermatopathology Preceptor in the Dermatology Department of the Dona Libânia Dermatology Center (CDERM) - Fortaleza (CE), Brazil.

Dermatologist Physician and Coordinator of the Dermatology Residency in the Dermatology Department of the Dona Libânia Dermatology Center (CDERM) Fortaleza (CE), Brazil.

Director and Dermatologist Physician of the Dona Libânia Dermatology Center (CDERM) - Fortaleza (CE), Brazil
} 


\section{CASE REPORT}

A 43-year-old woman, mulatto, reported the appearance of an asymptomatic tumor on her right thigh, which she had had for about 11 months. No comorbidities were reported.

The examination revealed an indurated hyperpigmented plaque with reddish-yellow nodules, on her right thigh, measuring $15 \mathrm{~cm}$ in diameter (Figure 1). An erythematous nodule was presented on her right buttock (Figure 2). The patient reported that these lesions were painless. A painless inguinal lymph node on the same side of the skin lesions was also revealed upon examination.

The histopathology of the skin lesion exhibited a slightly acanthotic epidermis, dermis and hypodermis with a diffuse infiltrate, consisting of lymphocytes, plasma cells and neutrophils (Figure 3). Occasional histiocytes containing intact inflammatory

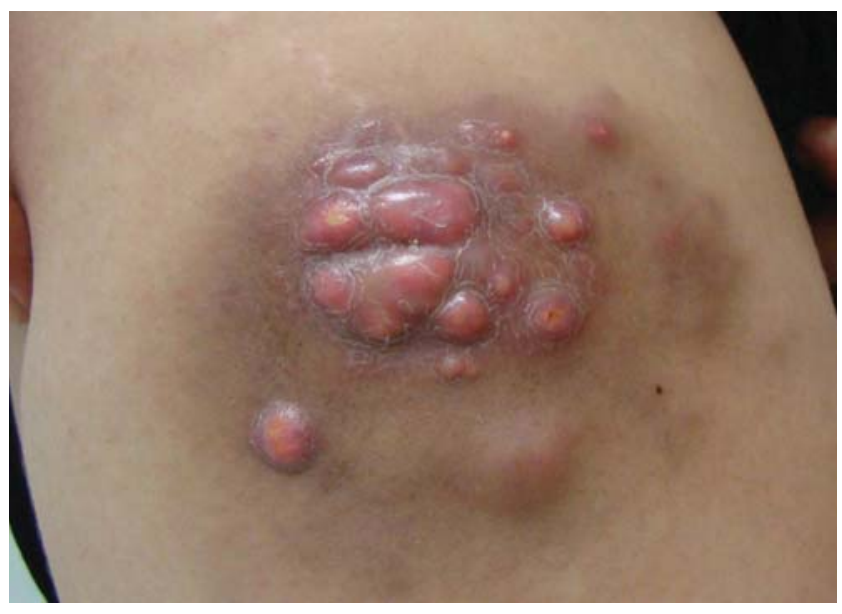

FIGURE 1: Indurated hyperpigmented plaque with reddish-yellow nodules on the right thigh

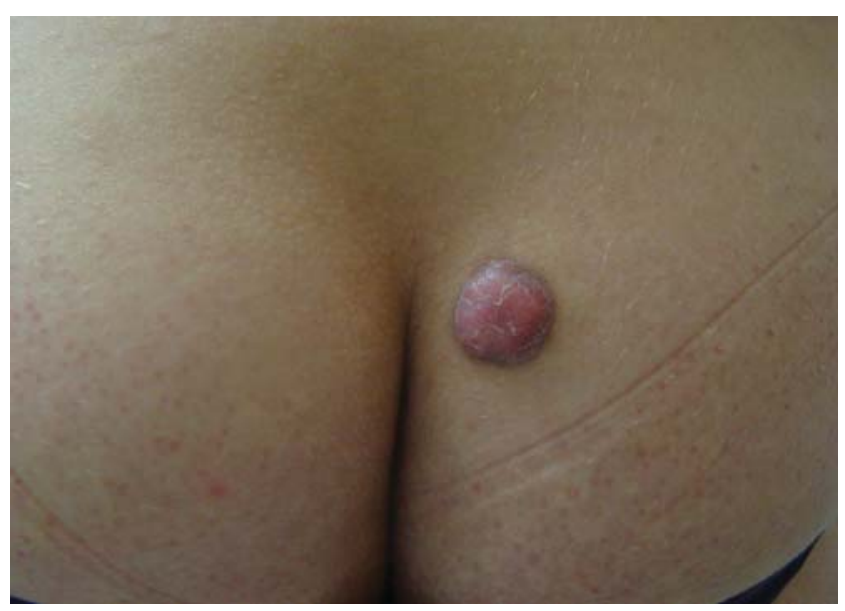

FIGURE 2: Erythematous nodule on the right buttock cells within the cytoplasm (emperipolesis) were also seen (Figure 4). Immunohistochemical studies revealed histiocytes with positivity for S100 and CD68 and negativity for CD1a. The histopathology of the inguinal lymph node showed dilated nodal sinuses with large numbers of histiocytes exhibiting emperipolesis (Figure 5).

Laboratory finds were microcytic anemia and polyclonal hypergammaglobulinemia. The image tests (ultrasound and CT) showed a marked thickening of the skin and the subcutaneous tissue located in the anterolateral region of the right thigh; enlarged lymph nodes up to $2 \mathrm{~cm}$ long located in the right inguinal chain; a normal-sized liver with the rare presence of homogeneous cysts of $0.5 \mathrm{~cm}$. The myelogram was normal.

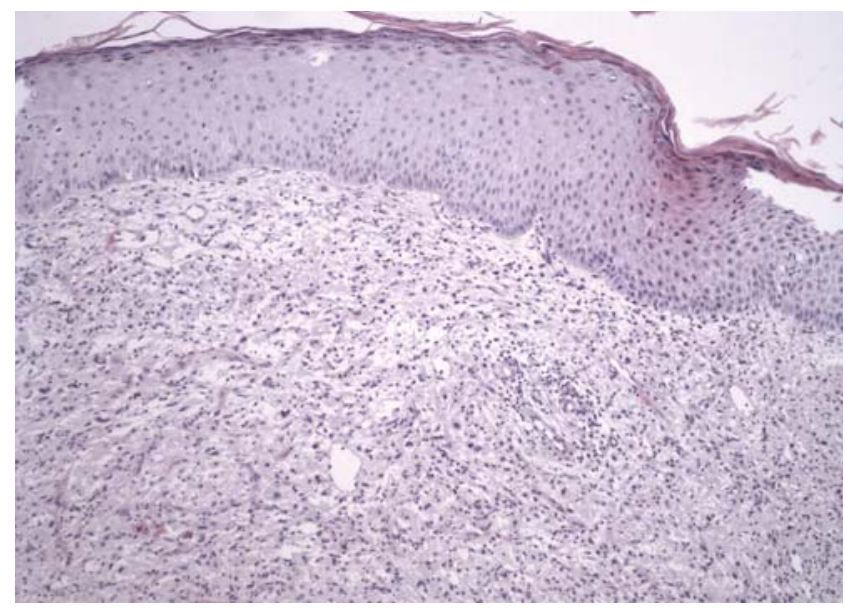

FIGURE 3: Skin biopsy. Difuse dermal infiltrates of histiocytes, lymphocytes, neutrophils and plasma cells. (H\&E stain, X100)

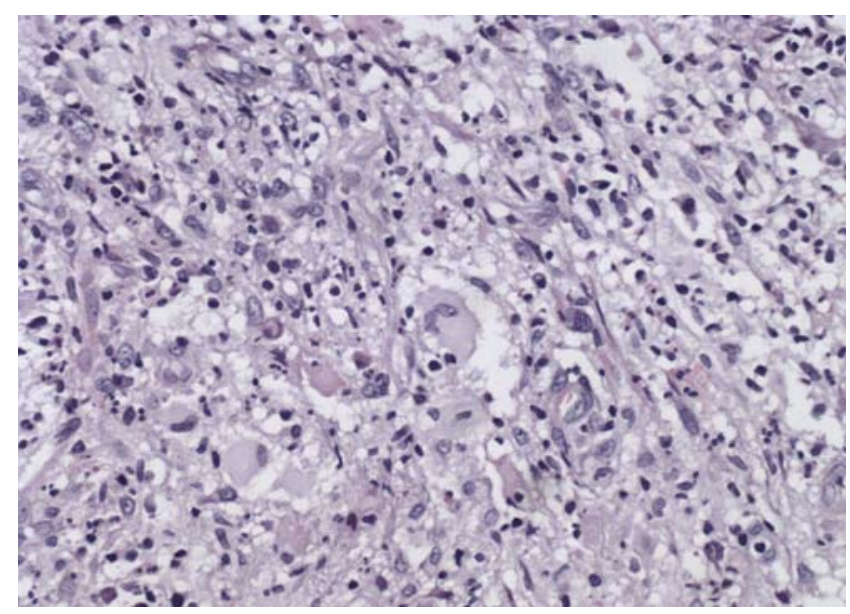

FIGURE 4: Skin biopsy. Few histiocytes with emperipolesis. (H\&E stain, X400) 


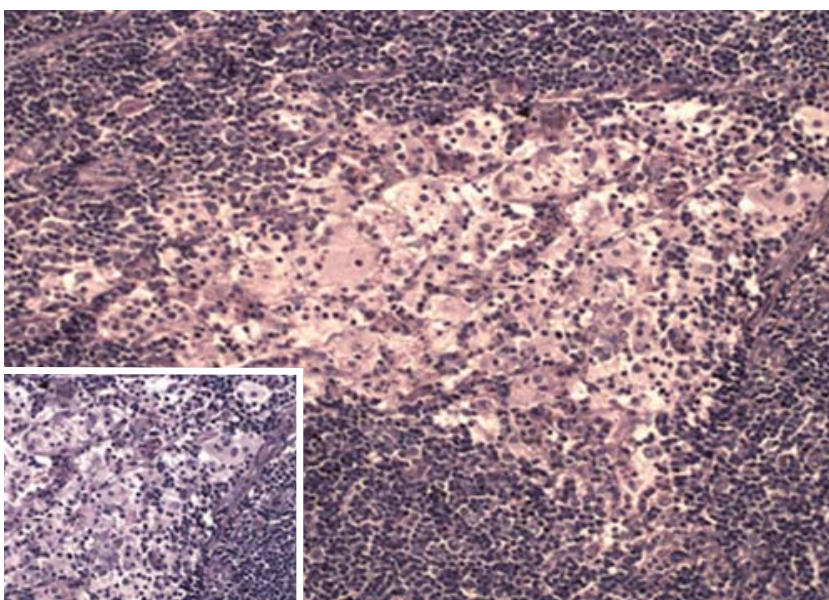

Figure 5: Lymph node biopsy. Dilated nodal sinuses with large amount of histiocytes exhibiting emperipolesis. (H\&E stain; X200, inset: X400)

The patient was referred to the oncology service for surgical treatment.

\section{DISCUSSION}

Sinus histiocytosis with massive lymphadenopathy is a rare self-limited pseudolymphomatous disorder of unknown etiology. The disorder is usually characterized by benign, extensive, cervical lymphadenopathy, accompanied by fever, polyclonal gammopathy and leukocytosis with neutrophilia. ${ }^{3}$

The histopathological features of SHML were first described in 1965 by Destombes. Four years later, SHML was recognized as a clinicopathological entity by Rosai and Dorfman. ${ }^{1}$ By 1988, as it became evident that other nodal and extranodal sites could also be affected and the term Rosai-Dorfman disease (RDD) was preferred. ${ }^{5}$

RRD affects all age groups, but predominantly people in the first and second decades of life. Males are slightly more susceptible to the disorder and it rarely affects people of Asian origin ${ }^{2,4}$ Lymphadenodopathy appears in $87 \%$ of the patients and is often cervical, bilateral, massive and painless. Inguinal (25.6\%), axilary $(23.7 \%)$ and mediastinal lymph nodes $(14.5 \%)$ may also be involved. ${ }^{3}$ But RDD only involves both nodal and extranodal sites in $28 \%$ of patients. ${ }^{5}$ Extranodal manifestations have been reported in $43 \%$ of cases and the skin is the most common site affected. ${ }^{4}$ Cutaneous manifestations are varied and appear as single or multiple maculae, papules, plaques or nodules, with colors ranging from red-brown to yellow. ${ }^{1}$

The classic histopathological features of RDD are dense diffuse or nodular infiltrates of foamy histi- ocytes, mixed with lymphocytes and plasma cells exhibiting emperipolesis. In emperipolesis, lymphocytes, plasma cells or neutrophils are captured but not digested by histiocytes. These specific types of histiocytes are called Rosai-Dorfman cells. The lymph nodes show capsular fibrosis and dilated nodal sinuses filled with foamy histiocytes that can exhibit emperipolesis. ${ }^{2,6}$ The histologic finds of cutaneous RDD are less obvious than those seen in the lymph nodes. Emperipolesis may be less conspicuous. ${ }^{7}$ Immunohistochemical testing shows strong and consistent positivity for S-100 protein and for CD68, but not for CD 1a. ${ }^{1}$ The patient displayed all of these histopathological features and the rendered diagnosis was RDD.

Owing to the variety of cutaneous manifestations of RDD, the differential diagnosis of the disorder affecting the skin is complex and must include cutaneous lymphoid hyperplasia, granuloma annulare, lymphocytic infiltrate of Jessner, interstitial granulomatous dermatitis, histiocytoma, Langerhans cell histiocytosis, lymphomas, melanoma and metastatic carcinomas. The diagnosis is more complex when the skin is the only organ affected or when there are minimal clinical signs of lymphadenopathy. ${ }^{8,9}$

The etiology of RDD remains unknown, but two hypotheses have been proposed as follows: a disturbance of cell-mediated immunity and a primary viral infection. Activated macrophages have been found in immunohistochemical tests. ${ }^{5}$ In addition, several reports have identified human herpes virus 6 and Epstein-Barr virus in visceral and cutaneous lesions, although the viral genesis could not be confirmed so far. RDD can be associated with immunemediated disease and seems to have a less favorable prognosis in these cases. ${ }^{1}$

Treatment depends on clinical manifestations. In many cases the lesions remain asymptomatic and heal naturally without requiring any treatment. However, the condition may be chronic with disseminated nodal, systemic involvement or destructive cutaneous lesions. Therapeutic modalities include corticosteroids, criotherapy, radiotherapy, surgery, high-dose thalidomide and alkylating agentes. ${ }^{1,9}$

In the described case, the exuberance of the cutaneous lesion and the absence of massive lymph node involvement made diagnosis difficult. The histopathological finds were essential for elucidation of the case. Despite the benign and self-limited disease, the patient presented severe cutaneous manifestation with chronic and progressive course, requiring more aggressive therapy. $\square$ 


\section{REFERENCES}

1. Becker M, Gaiser T, Middel P, Rompel R. Clinicopathologic challenge. DestombesRosai-Dorfman disease (DRDD) (sinushistiocytosis with massive lymphadenopathy). Int J Dermatol. 2008;47:125-7.

2. Landim FM, Rios Hde 0, Costa CO, Feitosa RG, Rocha Filho FD, Costa AA. Cutaneous Rosai-Dorfman disease. An Bras Dermatol. 2009;84:275-8.

3. Chang LY, Kou T, Chan HL. Extranodal Rosai-Dorfman disease with cutaneous, ophthalmic and laryngeal involvement: report of a case treated with isotretinoin. Int J Dermatol. 2002;41:888-91.

4. Gebhardt C, Averbeck M, Paasch U, Ugurel S, Kurzen H, Stumpp P, et al. A case of cutaneous Rosai-Dorfman disease refractory to imatinib therapy. Arch Dermatol. 2009;145:571-4.

5. Pitamber HV, Grayson W. Five case of cutaneous Rosai-Dorfman disease. Clin Exp Dermatol. 2003;28:17-21.

6. Wang KH, Chen WY, Liu HN, Huang CC, Lee WR, Hu CH. Cutaneous RosaiDorfman disease: clinicopathological profiles, spectrum and evolution of 21 lesions in six patients. Br J Dermatol. 2006;154:277-86.

7. Kroumpouzos G, Demierre MF. Cutaneous Rosai-Dorfman disease: histopathological presentation as inflammatory pseudotumor. A literature review. Acta Derm Venereol. 2002;82:292-6.
8. Uniyal SK, Beena KR, Ramesh V, Mukherjee A. Cutaneous Rosai-Dorfman disease preceding inguinal lymphadenopathy. Int J Dermatol. 2002;41:404-6.

9. Chan CC, Chu CY. Dapsone as a potential treatment for cultaneous Rosai-Dorfman disease with neutrophilic predominance. Arch Dermatol. 2006;142:428-30.
MAILING ADDRESS:

Paula Azevedo Borges Leal

Rua Pedro I, 1033 - Centro

60035-101 Fortaleza, CE

Brazil

E-mail: lealpauladl@gmail.com

How to cite this article: Leal PAB, Adriano AL, Breckenfeld MP, Costa IS, Sousa ARD, Gonçalves HS. RosaiDorfman disease presenting with extensive cutaneous manifestation - Case report. An Bras Dermatol. 2013;88(2):256-9. 